which the integral amount, during long periods of time, probably reaches five, or even ten seconds. In particular it seems that between 1769 and 1789 a retardation of the earth's rotation took place, and another between 1840 and I86r. Towards I 862 this slackening was followed suddenly by a well-marked acceleration, which possible persisted up to I $870 . "$

It may be added that the supposed variation does not seem to account for the lunar inequalities to which reference has been made.

\section{THE LADIES CONVERSAZIONE OF THE ROYAL SOCIETY.}

THE second of the two annual conversaziones of the Royal Society $\rightarrow$ the one to which both ladies and gentlemen are invited-was held in the room. of the Society at Burlington House, on the evening of Wedne tay in last week. As many of the scientific novelties exhibited were shown at the conversazione held in May, and have already been described in these columns (May 14), it is unnecessary to refer to them again. Only the new exhibits are therefore described in the present report.

In addition to Mr. Herbert Jackson's demonstration of the various degrees of phosphorescence of different subjects under the action of Röntgen rays, several other exhibits were devoted to methods used and results obtained with the rays. Prof. S. P. Thompson showed the production of electric dustshadows by Röntgen rays. When the rays are allowed to fall apon an electrified sheet of aluminium placed above a plate of ebonite, they carry electric charges to the plate and electrify it. If objects of metal are laid on the ebonite sheet they intercept the Röntren rays, and the part of the ebonite surface immediately shaded by them does not become electrified. On removing the ebonite plate and dusting upon it Lichtenberg's powders (mixed sulphur and red lead), the electric shadows become visible.

Prof. Thompson also showed a number of experiments on Köntgen's rays, viz.: ( $\alpha$ ) Cryptoscopic use of luminescent screens (revealing contents of packages, bones of hand, \&c.) by employment of focus tube (Jackson's pattern); (b) discharge of electroscope by Röntgen rays; $(c)$ new forms of X-ray tubes, including one for insertion in mouth; (d) apparatus of Ebert for producing luminescence by electric oscillations; $(e)$ stereoscopic Röntgen-ray photograph of rabbit.

Electric discharges in vacuum was the subject of exhibits by Messrs. Siemens, Bros., and Co. The exhibits were (I) a facsimile of Dr. Wm. Watson's vacuum tube of $\mathrm{I} 75 \mathrm{I}$. This was the first apparatus ever constructed for experiments on the electric discharge in a vacuum. The discharge from a Leyden jar passed through ten inches, and that from a frictional machine through three feet, the whole length of the tube. (2) Facsimile of Lord Cavendish's double barometer of 1751 , used by Dr. W.m. Watson in his researches. (3) Facsimile of Dr. Wm. Morgan's shortened barometer of i785. Dr. Morgan, by longcontinued boiling of the mercury in a barometer tube, produced a vacuum of such excellence that no discharge would pass, and equal, therefore, to that in a Hittorf or Crookes' tube of the present day. . It is probable that it would have sufficed for the production of Röntgen rays. (4) Apparatus for showing electric discharges at different degrees of exhaustion from $70 \mathrm{~mm}$. to o mm. (5) Photographs obtained ${ }^{-}$by means of Röntgen rays, showing relative transparency of different kinds of wood, minerals, and glass.

A series of striking. Röntgen photographs was shown by Dr. Macintyre. The marvellous advance made in Röntgen photography will be understood from the following statement of the subjects of Dr. Macintyre's pictures: (I) Hard Structures.Life-sized photographs of different parts of the human skeleton, including the spine, ribs, shoulder, elbow and other joints of the body. Some of the negatives were 24 by 20 inches. (2) Animal Kintodom.-A series of the animal kingdom, such as the fish, frog, adder, \&c. (3) Soft Tissues of the Body in Health and Disease.-Human heart in the living adult subject. The same in health and disease, also the tongue, tissues of the neck, including the larynx, \&c. (4) Instantaneous Photographs of Different Objects. - The time of exposure was unknown, but the most rapid picture shown was taken with a single flash of the tube, due to one vibration of the interrupter of a ten-inch spark coil.

Mr. J. J. II. Teall exhibited a series of photographs of the electric discharge at various stages during the exhaustion of a Crookes' bulb of the Jackson type.

A small dynamo for measuring the permeability and hysteresis of iron was exhibited by Prof. W. E. Ayrton and Mr. T. Mather. The specimen to be tested, which may be in the form of a round bar or a bundle of thin plates, forms the yoke of the dynamo, and through a coil surrounding it is passed the magnetising current, the winding of this coil being so arranged that the current in amperes is numerically equal either to the magneto-motive force per centimetre of the bar, or to one-tenth of that value. When the armature is run at a speed of II 50 revolutions per minute, the induction per square centimetre in the bar is approximately equal to ro,ooo times the E.M.F. in volts produced. Hence not merely the magnetising current but also the induction is measured by a steady deflection, and not, as is usual, by the instantaneozts swing of a ballistic galvanometer. The magneto-motive force required for the air-gap and joints is determined experimentally by the use of a standard bar whose $\mathrm{B} \mathrm{H}$ curve is accurately known.

Mr. J. Frith demonstrated the different effects produced by superimposing a small alternating current on a direct current arc according as cored carbons or solid carbons are employed. When a small alternating current is superimposed on a direct current arc formed with cored carbons, the oscillations of potential difference and current are in the same direction for all frequencies higher than about $I_{2} \frac{1}{2}$ periods per second. On the contrary, if the carbon be solid, the oscillations of potential difference and current are in the opposite direction for all frequencies tried up to 256 periods per second. This difference was exhibited by the visible motion of ammeter and voltmeter needles.

Microscopic internal flaws inducing fracture in steel axles, rails, and propeller shafts were shown by Mr. T. Andrews. This exhibit consisted of a series of accurate micrographs taken at a high magnifying power, illustrative of the microscopically visible and tangible micro-flaws, almost invariably present in considerable number, in steel railway axles, rails, tires, propeller shafts, \&c. The presence of these germs of metallic disease in steel (mostly due to sulphur and other impurities) greatly influences the deterioration by fatigue of the metal, and they are a potent factor in inducing the sudden fracture of engineering constructions in steel.

Mr. J. Macfarlane Gray exhibited a multiplication frame. In this contrivance, for obtaining the product of two multidigital numbers, product cards, as on "Napier's rods," are set for one of them upon a sole frame, and sliders on a grid are shifted to set up the other. Each slider has a pane of plass at mid-length. The grid is fitted to the sole frame upon a pair of stepped guides, and is slid along over the cards one figure at a time. At each step the component products in one of the vertical columns of the common multiplication rule are exhibited at the panes and added mentally. In this way the final product is obtained without transcribing the intermediate products.

Exhibits illustrative of applications of the mathematical theory of frequency were shown by the Applied Mathematics Department of the University College, London. They included: (I) Diagram illustrating the relative variation of different organs in men and women of diverse races, by Miss Alice Lee, G. U. Yule, and K. Pearson. (2) Diagrams showing that 25 per cent. of the married population produce $5^{\circ}$ per cent. of the next generation-Reproductive Selection, by K. Pearson. (3) Diagrams illustrating barometric frequency over the British Isles, by Miss Alice Lee, C. Jakeman, and K. Pearson. (4) Frequency recording barometer, by G. U. Yule and Cambridge Instrument $\mathrm{Co}$. (5) Amplified integrator for finding mean, mean square and mean cubic deviations, and frequency skewness, by Amsler-Laffon. (6) Prcf. Ranke's craniophor, used in comparing variation of skulls, as determined by English and German methods, by A. MartinLeake and K. Pearson. (7) Skew binomial machine, by G. U. Yule. (8) Model of contour-tracer for finding areas of section of small objects.

Stereoscopic views of algebraic spherical catenaries and cryrostat curves were exhibited by Prof. A. G. Greenhill and Mr. T. I. Dewar. The mathematics of the spherical catenary are discussed in a paper by Prof. Greenhill in the volume of the Proceedings of the London Mathematical Society for the current year, and a diagram of a closed algebraical one with five

No. [390, VOL. 54] 
loops is there given. This was the first case in which it had been found possible to express the integral

$$
\int \frac{A d z}{\left(\mathrm{I}-z^{2}\right) \sqrt{ }}
$$

algebraically, where $Z=\left(1-z^{2}\right)(h-z)^{2}-A^{2}$, and $A$ and $h$ are constants. The accompanying diagram is for the next possible case of seven loops, and has been made by Mr. T. I. Dewar. The circle in the lower hemisphere shows where the pressure of the chain on the sphere becomes zero; below that, the obtain the solid effects with this instrument. The lenses may be angled, and moved to and from the centre at will. Also the distance can be varied between the picture and the lenses. The distance between picture and lenses is greater than usual, to. allow a wider mirror, which is advantageous.

A number of cloud photographs taken in different parts of the ocean world were exhibited by Captain D. Wilson-Barker; and Mr. F. H. Worsley-Benison exhibited a series of seascape photographs. The photographs were enlargements in carbon. The whole picture in each subject was the result of one exposure only.

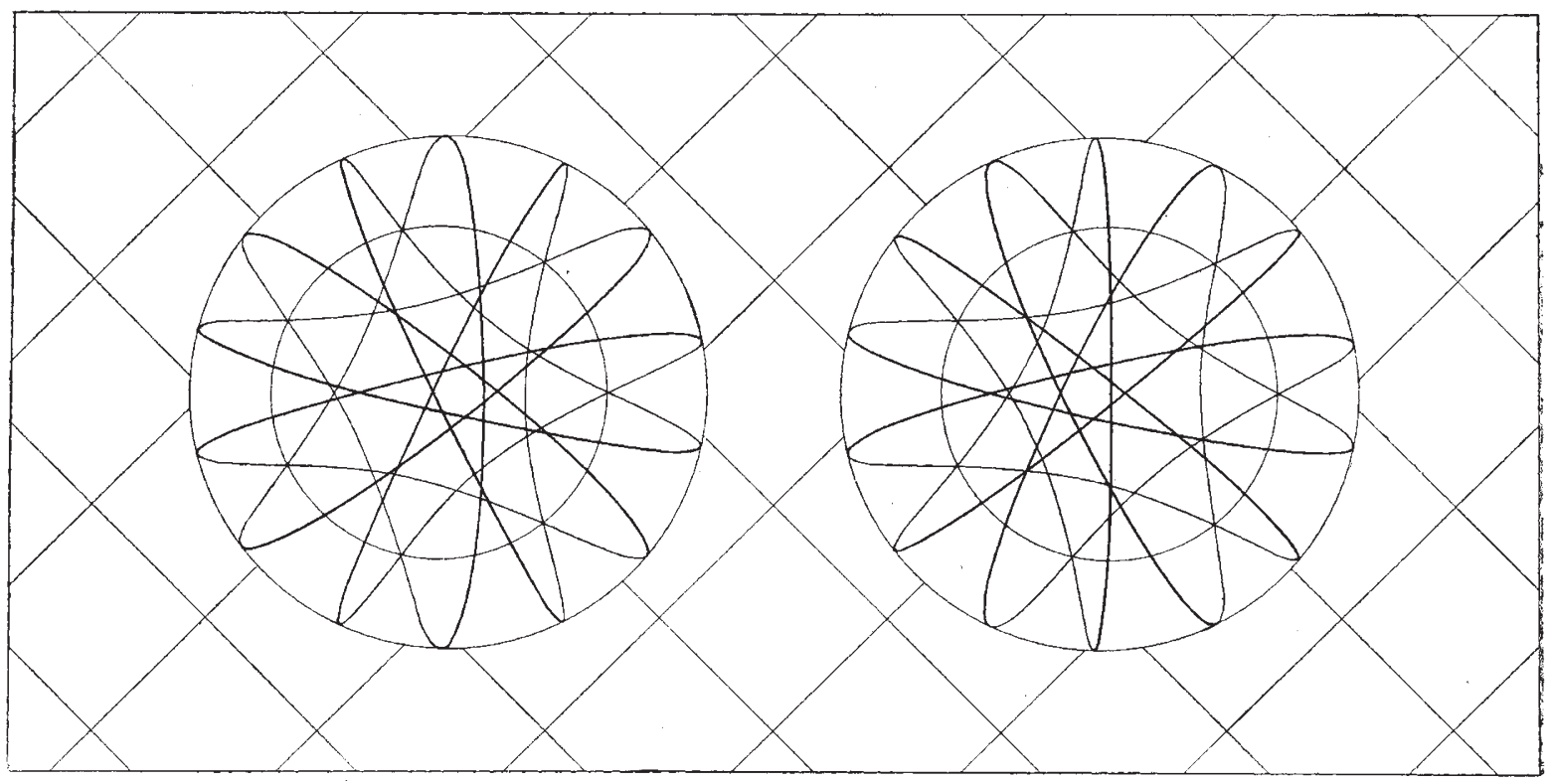

chain is supposed to rest on the interior of the hollow sphere. The tesselated pavement indicates the position of the directrix.plane. The tension at any point of the catenary is the same as in a chain hanging vertically to this plane, like a similar property in the plane catenary. A great many other cases with different numbers of loops have been examined, but the results turn out to be imaginary

Mr. Robert L. Mond exhibited the following apparatus intended for the Davy-Faraday Research Laboratory of the Royal Institution: (I) Kilogram automatic balance (Rueprecht, Vienna). (2) Prism automatic spectroscope (Kruss, Hamburg). (3) I-inch spectrometer after Landolt and Brithl (Hildebrandt, Freiberg). (4) Hiifner photo-spectrometer (Albrecht, Tiibingen). (5) Large polariscope 6-inch Landolt. (6) Small Landolt polariscope (Schmidt and Haensch). (7) Berthelot platinum bomb (Golaz, Paris). (8) Glass scale cathetometer (R. Fuess, Berlin). (9) Petrographical microscope (R. Fuess, Berlin). (Io) Millivolt meter reading Centigrade degrees for Le Chatelier Thermophile (Keiser and Schmidt, Berlin). (II) Compensation box of Physikalische Reichsanstalt, Berlin (Wolff, Berlin). (I2) Set of standard resistances (Wolff).

Prof. Dewar showed a portable apparatus for the production of liquid air and oxygen. A working model of support for large specula, designed to leave the line of collimation undisturbed, was exhibited by Dr. G. Johnstone Stoney.

Mr. F. McClean exhibited (I) photographic stellar spectra of Type III., including spectra of $o$ Cetus (showing bright lines $\mathrm{H} \gamma$ and $\mathrm{H} \delta$ ), $\alpha$ Taurus, $\alpha$ Orion, $\alpha$ Scorpio, $\beta$ Andromeda, a Cetus, $\delta$ Ophinchus, $\mu$ Gemini, $\delta$ Virgo, $\beta$ Pegasus, $\alpha$ Hercules (2) Photographic spectrum of Secchi's Type IV. This was a

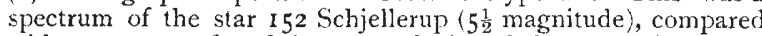
with spectrum of a Orion. (3) Series of photographic spectra of the variable star $\beta$ Lyra, compared with spectra of $\beta$ Orion and $\delta$ Taurus.

A new form of stereoscope was shown by Sir David L. Salomons. This stereoscope has been designed to suit the vision of all persons, without straining the eyes. Many individuals who are unable to use the ordinary stereoscope have been able to
Coming now to natural science: Models of the flowers of Aristolochia gigas from Brazil, and of Statelia sigantea from Natal (made by Miss Emett for the Museums of the Royal Gardens, Kew) were exhibited by the Director, Royal Gardens, Kew. Flowers with livid colouring and exhaling indol or some allied body occur in different families of the vegetable kingdom. Kerner ("Natural Mistory of Plants," translated by F. Oliver, vol. ii. pp. 197-200) thus describes them: "Flowers provided with indoloid scents resemble animal corpses in their colouring, having usually livid spots, violet streaks and red-brown veins on a greenish or fawn-coloured background." "Such flowers . . are always visited by carrion-flies or dung-bettles in abundance."

The Director of the Royal Gardens also showed photographs of Hrematozoa of fly disease of South Africa (exhibited on behalf of the Government of Natal). For the last half-century the Tsetse-fly has been notorious as a terrible scourge to livestock, and the most formidable of impediments to colonisation in Equatorial and South Africa. Surgeon-Major Bruce has now discovered that the fly is itself innocuous, and is only fatal to animals when it is the carrier of a flagellated infusorian (hamatozoon) which it introduces into their blood.

Two coloured casts of the New Zealand lizard, Hatteria or Sphenodon, were exhibited by Prof. Ray Lankester. The casts were taken at the Zoological Society's (rardens from a fullgrown specimen immediately after death, and painted by Prof. Lankester, so as to give the natural colours. Stuffed specimens of lizards' skins are very difficult to prepare with any approach to natural form and folding of the skin. Such casts as those shown are useful as preserving form and pose.

Mr. Frederick James exhibited examples of British Lepidoptera (Khopalocera) denuded of scales to illustrate their neuration. In each specimen the scaleless left fore and hind wings illustrated the neuration of the genus.

An experiment to ascertain the period at which larva are sensitive to surrounding colours, formed the subject of an exhibit by Prof. Poulton. The larve of Amphidasis betularia were, after hatching, surrounded with green leaves and shoots. During

NO. I 390 , vOL. 54] 
each of the stages of growth a batch of larva was removed and surrounded by dark twigs, and at the end of the stage restored to the green leaves. By comparing the colours of the mature larvæ in the different batches, it is possible to determine the period of larval susceptibility.

The following forms of variation in butterflies of the genus Heliconizus, of Tropical America were exhibited by Mr. W. F. H. Blandford. (I) Variation in Heliconizts erato, L. There are three main types with the basal patch of the hind-wings, respectively, red, blue, or green. The green form is dominant in Panama; it occurs throughout Central America, but not in South America, except sparingly in Columbia and Venezuela. At Sao Paulo, on the Upper Amazons, the blue form alone occurs, or the basal patches may be obsolete. (2) Variation in Heliconizes thelxiope. Huibn., and Heliconius vesta, Cram. Both forms occur together, and are very variable in Cayenne and the Lower Amazon Valley. Further west definite parallel geographical races occur of both. Heliconizss thelxiope is connected by intermediate forms in Cayenne with Heliconius melpomene, L., a widely distributed species, which occurs in the Amazon Valley at Santarem and Obydos only, and is not found in the humid forest. In Bolivia Heliconius vesta merges into Heliconizus phyllis.

Mr. W. Saville Kent showed interesting photographs and specimens illustrating the natural history and ethnology of Australia. The Hon. Walter Rothschild exbibited a group of recently described and other rare Birds of Paradise and Bowerbirds.

During the evening four lantern demonstrations were given in the meeting room of the Society. Prof. A. C. Haddon showed a series of slides illustrating the evolution of the cart, and another which illustrated the evolution of the Irish jaunt ing-car. The Altels avalanche, which occurred in September 1895, was described with photographs by Dr. Tempest Anderson, and Prof. Herkomer gave a demonstration of his new gravure process. Prof. Dewar dealt with liquid air, and showed the following experiments illustrative of low temperature effects :Filtering liquid air; vacuum vessels boiling at $35^{\circ} \mathrm{F}$. below the freezing point; colour and absorption spectra; spheroidal state; solid alcohol; frozen soap-bubble ; distilling mercury and phosphorus; liquefaction and solidification of gases; fusible metal spring; brittle indiarubber and its expansion by cold; the diamond burning in liquid oxygen; magnetic oxygen; photographic action and phosphorescence ; ignition by means of a lens of liquid air ; cooling a vessel $380^{\circ} \mathrm{F}$. below the freering point, until the air of the room condenses on the surface to the liquid state.

The Lords of the Committee of Council on Education have arranged for the public exhibition, in the Westerr Galleries of the Science Museum at South Kensington, of a number of the objects shown at the soirée. The exhibition will remain open to the public for about a fortnight.

\section{ON THE ROTATION OF THE EARTH.'}

THE recent discovery of periodical variations of terrestrial latitudes demands a revision of the actual theory of the rotation of our planet. This theory, based upon the hypothesis of the absolute rigidity of the earth, admits of variations of this kind, but very different in their laws from those of the observations. The period of revolution of the terrestrial poles given by the theory is one of about ten months. That which the observations give us lasts nearly fourteen months. Still further, the attentive analysis of the observations of the latitudes, executed of late by Mr. Chandler, shows us that the movement of the terrestrial poles is compounded of two others, of which the periods are, the one of 430 days, and the other of twelve months.

Following the order of the ideas established in the science by the celebrated cosmogenic hypothesis of Laplace, we ought to attribute this disagreement of the theory and the observations to the interior fluidity of the earth. But the illustrious physicist, Lord Kelvin, does not admit that the fluid nucleus of the earth may be of considerable enough dimensions. The greatest part of the astronomers of our day adhere to this opinion. They refer the said discordance to the terrestrial glube being elastic.

1 Abridged translation of a paper by Th. Sloudski, Professor at the University of Moscow (Bulletin de la Société Impériale des Naturalistes de Moscou. Année I895, No. 2).
In considering the hypothesis of a thin rigid crust of the earth as contrary to all given physics, the celebrated English physicist affirms in his memoir "On the Rigidity of the Earth" Phil. Trans., I863, and in the first edition of the "Treatise on Natural Philosophy" (\$\$ 847 and 848 ), that this hypothesis is also incompatible with the observations of the precession and of the nutation. On subsequently withdrawing certain of these astronomical objections, he has replaced them by some others.

To be able to appeal to objections of this kind, the theory of the rotation of the earth considered fluid in its interior ought to have been previously established. Lord Kelvin has not done it. He has limited himself to enunciating in general terms the principal propositions of this theory. To be able to judge of the said objections of the celebrated English physicist, the theory in question must be previously established.

The problem of the rotation of the earth-supposed fluid in its interior--was approached by W. I Iopkins in 1839 (Phil. Trans., I839-40-42); but the state in which hydrodynamics then was found, did not permit the English savant to treat the matter in a satisfactory manner. The more recent attempts to solve this difficult problem have not been more successful.

We shall endeavour in the present article to give a more perfect solution of this important problem. To render this task more easy, we shall assume that the nucleus of the earth is homogeneous, and of the form of a planetary ellipsoid.

The success of our task is assured by the beautiful researches of our clever geometrician, Prof. N. Joukovsky, relative to the movement of a solid body with cavities filled with an incom pressible homogeneous fluid. We have only to apply these researches to our special problem. We hope to lessen the difficulties of this application by the supposition that the rotatory mution of the entire terrestrial mass differs very little from the uniform rotation. The proposition of the celebrated Laplace, relative to the effect of friction of the fluid parts of the earth upon its rotatory motion, affords us a solid foundation for the said supposition ("CEuvres Complétes de Laplace," tome v. p. 283).

We shall commence our article with an abridged exposition of the theory of the rotation of a solid body, which has a cavity filled with an incompressible homogeneous fluid. In the development of the principal formulie of this theory we shall employ the most simple method, that of the illustrious Poisson. We shall equally profit by them in our transformations of the hydrodynamical equations.

(The final paragraphs, after thirty large octavo pages of intricate mathematics, are as follows.)

We have taken our problem with some considerable restrictions relative to the form, to the position, to the structure, and to the movement of the terrestrial nucleus. This renders almost useless the detailed comparison of our results with the given astronomical ones. We will only say some words relative to one of these results, of which the generality is indubitable.

The hypothesis of a fluid nucleus of the earth being admitted, and the exterior forces neglected, the movement of the terrestrial poles ought to be composed of two periodic movements. The period of the former of these movements is perhaps of twelve or fourteen months, that of the second ought to be pretty nearly a day.

The astronomical observations do not show us this second movement of the poles. Is not this a reason for taking exception to the hypothesis of the fluidity of the earth in its interior? By no means. It is in the first place possible that the smallness of the amplitude of the movement in question may make it unrecognisable. The smallness of the factors $\mu_{2}, \nu_{2}$ renders this supposition probable. Secondly, it may also be admitted that the want of the appropriate observations causes us to ignore for the present this movement, although its amplitude may be appreciable. One may also suppose that the period of the movement in question, from the usual order of astronomical observations, appears to us to be a period of twelve or of fourteen months. For instance, should the said period be equal to twenty-four sidereal hours exactly, and the observations of the latitude of any astronomical observatory be made every midnight during a good many years, the result of them will be the period of twelve months.

This last supposition appears to us worthy of attention, because according to our opinion the explanation of the period of twelve months by meteorological causes, as is adopted at present by some astronomers, wants probability.

NO. I 390, VOL. 54] 